\title{
Níveis de farelo de melancia forrageira em dietas para ovinos ${ }^{1}$
}

\section{Raimundo Luiz Nunes Vaz da Silva ${ }^{2}$, Gherman Garcia Leal de Araújo ${ }^{3}$, Eliomar Pereira do Socorro ${ }^{4}$, Ronaldo Lopes Oliveira ${ }^{4}$, Américo Fróes Garcez Neto ${ }^{4}$, Adriana Regina Bagaldo ${ }^{4}$}

\author{
${ }^{1}$ Pesquisa financiada por MCT/CNPq, EMBRAPA, UFBA \\ 2 IFET-BAIANO Campus, Catu-BA. \\ ${ }^{3}$ Embrapa Semi-Árido. \\ ${ }^{4}$ Departamento de Produção Animal - MEV/UFBA.
}

RESUMO - Com o objetivo de estudar a inclusão de 20, 35, 50, 65 ou 80\% de farelo de melancia forrageira (Citrullus lanatus cv. citroides) (FMF) em dietas à base de feno de guandu (Cajanus cajan), foi realizado um ensaio de digestibilidade utilizando-se 20 cordeiros com 6 meses de idade e peso vivo de 11,2 $\pm 1,2 \mathrm{~kg}$. O experimento constou de 20 dias de adaptação e 5 de coleta total de sobras e de fezes. O farelo de melancia forrageira e o feno de guandu apresentaram 95,3 e 95,75\% de matéria seca (MS), 18,7 e 16,8\% de proteína bruta (PB) e 38,8 e 64,3\% de fibra em detergente neutro (FDN). Os níveis de farelo de melancia forrageira determinaram aumento quadrático nos consumos de MS, MO, PB, FDN, FDA, hemicelulose e carboidratos totais. O consumo de extrato etéreo não foi alterado, mas o consumo de CNF teve aumento linear conforme aumentaram os níveis de farelo de melancia forrageira. Os coeficientes de digestibilidade de MS (58\%), PB (69\%), FDN (41\%) e EE (85\%) não foram influenciados pelo nível de farelo de melancia forrageira. As digestibilidades de MO (54 a 62\%), FDA (36 a 49\%) e carboidratos totais (47 a 58\%) variaram linear e positivamente, enquanto a digestibilidade da hemicelulose teve comportamento inverso. As dietas proporcionaram consumo de matéria seca que atendeu a exigência dos animais. Os coeficientes de digestibilidade observados foram satisfatórios. O farelo de melancia forrageira pode ser indicado para compor dietas à base de feno de guandu em níveis de 35 a 66\% da matéria seca.

Palavras-chave: alimentos, aspectos digestivos, cordeiros, nutrição

\section{Levels of forage watermelon meal in diets for sheep}

\begin{abstract}
In order to study the inclusion of forage watermelon (Citrullus lanatus var. Citroides) meal (FWM) in pigeon pea hay based diets (Cajanus cajan) (PPH), a digestibility trial in sheep was carried out for testing five levels of FWM (20, 35, 50, 65 and 80\%). Twenty lambs with an average age of six months and live weight of $11.2 \mathrm{~kg}( \pm 1.2)$ were used. The experimental period was twenty days for adaptation and five days for total refuses and feces collection. The chemical composition of diet ingredients was determined, being the levels of dry matter (DM) 95.3 and 95.75\%, crude protein (CP) 18.7 and $16.8 \%$, neutral detergent fiber (NDF) 38.8 and 64.3\% for WFM and PPH, respectively. The water, DM, organic matter (OM), CP, ether extract (EE), NDF, acid detergent fiber (ADF), hemicellulosis (HCEL), non-fibrous carbohydrates (NFC), total carbohydrates (TCOH) intakes, as well as the DM, MO, CP, EE, NDF, ADF, HCEL and TCOH digestibilities were accurately measured. The DM, OM, CP, NDF, ADF, HCEL and TCOH intakes showed a quadratic behavior according to the FMF levels. The ether extract intake remained unchanged, while the NFC intake was linearly positive. The DM (58\%), MO (69\%), NDF (41\%) and EE (85\%) digestibility coefficients were not significantly influenced by the forage watermelon meal levels. The OM (54 to 62\%), ADF (36 to 49\%) and TCOH (47 to 58\%) digestibility ranged linear and positively, while the HCEL digestibility showed the opposite behavior. The experimental diets provided dry matter intake enough to meet the animal requirements. The digestibility coefficients observed were satisfactory. The forage watermelon meal can be used in the guandu hay based diets in the levels from 35 to $66 \%$ of dry matter.
\end{abstract}

Key Words: digestive aspects, foods, lambs, nutrition

\section{Introdução}

A ovinocaprinocultura é uma atividade sócioeconômica importante para famílias nordestinas e constitui alternativa capaz de proporcionar meios adequados à produção animal, desonerar custos e viabilizar a sustentação da população rural pelo aporte de renda e proteína alimentar.

Atualmente, buscam-se opções alimentares para viabilizar a produção animal em duas vertentes. A primeira 
é o estudo de espécies nativas ou exóticas com potencial para utilização na alimentação animal. A outra é a avaliação do potencial dos resíduos gerados como co ou subprodutos para alimentação animal, a partir destas espécies exploradas com finalidade energética.

Entre as espécies nativas estudadas para uso na alimentação animal, incluem-se a maniçoba, o angico, a catingueira, o juazeiro e as cactáceas, como o facheiro e mandacaru (Cândido, 2005). Outras espécies exóticas são apontadas como forrageiras, por exemplo, palma, Stylosanthes capitata e macrocephala, leucena, gliricídia e guandutaipeiro (Gomide et al., 2006). Contudo, são escassos os trabalhos sobre a utilização de melancia forrageira em dietas para ruminantes com bases cientificamente fundamentadas na literatura. A melancia forrageira, conhecida também como melancia-de-porco, do mato, de cavalo ou caiana, é de notável resistência à seca, de fácil cultivo e bem aceita pelos ruminantes (Silva, 2003). Entretanto, os níveis de inclusão viáveis nas dietas e os aspectos relacionados à sua utilização digestiva, como potencial de consumo, coeficientes de digestibilidade e limites de inclusão não estão ainda esclarecidos, embora essas informações sejam importantes para o aperfeiçoamento de seu uso na alimentação animal. Véras et al. (2005) avaliaram o efeito da substituição do milho moído por farelo de palma (0, 33, 67 e 100\%) sobre o consumo e a digestibilidade dos nutrientes e observaram que os consumos de MS, MO, FDN e PB não foram influenciados pelos níveis de substituição do milho pelo farelo de palma nas dietas testadas, entretanto, o aumento dos níveis de farelo de palma provocou redução dos coeficientes de digestibilidade dos nutrientes estudados. Silva et al. (2007) estudaram os efeitos da incorporação de feno de maniçoba (20; 40; 60 e 80\%) em dietas para ovinos Santa Inês e verificaram que o consumo de MS das dietas não foi afetado. Contudo, os coeficientes de digestibilidade de MS, MO, PB, FDN, FDA e carboidratos totais (CT) reduziram com o aumento dos níveis de feno de maniçoba.

A transformação da melancia forrageira em farelo no seu estágio mais adiantado de maturação é uma forma de conservar alimento para os animais no semi-árido. $\mathrm{O}$ farelo pode ser estocado por 3 a 4 anos se isento de umidade. Esse tempo de conservação, adicionado aos 8-12 meses que a forrageira pode ser conservada naturalmente (armazenada no campo a céu aberto), constitui sua principal vantagem como alimento alternativo. Assim, realizou-se este estudo com o objetivo de verificar o nível mais adequado de inclusão do farelo de melancia forrageira em dietas à base de feno de guandu para ovinos, com base no consumo e na digestibilidade dos nutrientes da dieta.

\section{Material e Métodos}

O experimento foi realizado na Embrapa Semi-Árido, situada na rodovia BR 428, Km 152, Zona Rural, Petrolina, Pernambuco, durante os meses de setembro e outubro de 2001.

Os animais foram sorteados nos tratamentos e alojados em gaiolas de metabolismo dispostas em galpão coberto. $\mathrm{O}$ ensaio teve duração de 25 dias ( 20 de adaptação e 5 de coleta total de fezes e sobras).

Foram utilizados 20 cordeiros sem padrão racial definido (SRD), nativos, com 6 meses de idade e peso vivo médio de 11,2 kg $( \pm 1,2)$, oriundos de propriedades da região. O baixo peso para a idade dos animais neste experimento está relacionado à origem dos animais, de região semi-árida, com ambiente inóspito, e às condições de criação, com severa restrição alimentar, sobretudo nos períodos de estiagem prolongada. Os animais, depois de identificados com brincos numerados, foram vermifugados, suplementados com vitaminas A, D e E e alojados em gaiolas de metabolismo individuais, confeccionadas em madeira, com piso ripado, com separação de $5 \mathrm{~cm}$ entre as ripas, comedouro, bebedouro, saleiro e bandeja telada para separação de fezes e urina. Foram coletadas as fezes retidas na tela da bandeja e a urina retida em recipiente situado sob a gaiola.

Os alimentos utilizados foram farelo de melancia forrageira (Citrullus lanatus cv. Citroides) e feno de guandu (Cajanus cajan). Na análise da composição dos alimentos e das dietas (Tabela 1), foram determinados os teores de matéria seca (MS), matéria orgânica (MO), proteína bruta (PB), cinzas, extrato etéreo (EE), fibra em detergente neutro (FDN), fibra em detergente ácido (FDA), hemicelulose, carboidratos não-fibrosos (CNF), carboidratos totais (CT), nutrientes digestíveis totais (NDT), taninos totais, cálcio (Ca), fósforo $(\mathrm{P})$, magnésio $(\mathrm{Mg})$, potássio $(\mathrm{K})$, sódio $(\mathrm{Na})$, cobre $(\mathrm{Cu})$, ferro $(\mathrm{Fe})$, manganês $(\mathrm{Mn})$ e zinco $(\mathrm{Zn})$.

$\mathrm{O}$ farelo de melancia forrageira foi obtido a partir da passagem do fruto integral in natura em máquina de fazer raspas de mandioca e o material resultante foi espalhado em camadas sobre terreiro cimentado para desidratação ao sol durante 36 horas e revirado duas vezes ao dia. Em seguida, o material desidratado foi desintegrado em moinho utilizando-se peneira com malha de $10 \mathrm{~mm}$ de diâmetro.

O feno de guandu foi preparado ao sol até que sua umidade foi reduzida a aproximadamente $10-15 \%$ e picado em partículas de 4 a $5 \mathrm{~cm}$ em picadeira motorizada. Água e mistura mineral completa foram fornecidas à vontade aos animais durante todo o período experimental.

As dietas foram formuladas com base de matéria seca, convertida à matéria natural, e fornecidas duas vezes ao dia, às 8 h e às 15h30, ajustando-se a sobra diária para 20\% em 
Tabela 1 - Composição dos alimentos e das dietas experimentais

\begin{tabular}{|c|c|c|c|c|c|c|c|}
\hline \multirow[t]{2}{*}{ Fração $(\% M S)^{1}$} & \multicolumn{2}{|c|}{ Alimento } & \multicolumn{5}{|c|}{ Nível de farelo de melancia forrageira (\%) } \\
\hline & Farelo de melancia forrageira & Feno de guandu & 20 & 35 & 50 & 65 & 80 \\
\hline Matéria seca & 95,35 & 95,71 & 95,64 & 95,58 & 95,53 & 95,48 & 95,42 \\
\hline Proteína bruta & 18,73 & 16,77 & 17,16 & 17,46 & 17,75 & 18,04 & 18,34 \\
\hline Cinzas & 11,87 & 9,74 & 10,17 & 10,49 & 10,81 & 11,12 & 11,44 \\
\hline Extrao etéreo & 10,39 & 3,92 & 5,21 & 6,18 & 7,16 & 8,13 & 9,10 \\
\hline Hemicelulose & 4,76 & 21,53 & 18,18 & 15,66 & 13,15 & 10,63 & 8,11 \\
\hline Carboidratos não-fibrosos & 20,19 & 5,30 & 8,28 & 10,51 & 12,73 & 14,98 & 17,21 \\
\hline Carbohidratos totais & 59,01 & 69,57 & 67,46 & 65,87 & 64,29 & 62,71 & 61,12 \\
\hline Nutrientes digestíveis totais & 62,08 & 52,51 & 54,42 & 55,86 & 57,30 & 58,73 & 60,17 \\
\hline Taninos & 1,96 & 4,71 & 4,16 & 3,75 & 3,34 & 2,92 & 2,51 \\
\hline Cálcio & 0,42 & 2,95 & 2,44 & 2,06 & 1,69 & 1,31 & 0,93 \\
\hline \multicolumn{8}{|l|}{ Fração $(\mathrm{ppm})^{2}$} \\
\hline Cobre & 24,33 & 26,80 & 26,31 & 25,94 & 25,57 & 25,19 & 24,82 \\
\hline Ferro & 110,43 & 347,10 & 299,77 & 264,27 & 228,77 & 193,26 & 157,76 \\
\hline Manganês & 34,66 & 79,15 & 70,25 & 63,58 & 56,91 & 50,23 & 43,56 \\
\hline Zinco & 53,29 & 70,01 & 66,67 & 64,16 & 61,65 & 59,14 & 56,63 \\
\hline
\end{tabular}

${ }^{1}$ Análises realizadas nos Laboratórios da UFBA, Embrapa Semi-Árido.

2 Empresa Baiana de Desenvolvimento Agrícola.

relação à dieta oferecida, por animal. A composição protéica das dietas variou conforme os níveis de farelo de melancia forrageira. Foram feitas anotações diárias da quantidade de ração fornecida e das sobras de cada animal, além de amostragem semanal do concentrado, do volumoso e das sobras para análises posteriores.

Foram avaliados cinco níveis de farelo de melancia forrageira (20, 35, 50, 65 e 80\%) na dieta com feno de guandu (Tabela 1). Nos últimos cinco dias do período experimental, foram colhidas diariamente amostras do alimento oferecido, das sobras do dia anterior e das fezes produzidas pelos animais. Amostras de 200 g correspondentes a cada nível de farelo de melancia forrageira eram retiradas logo após o preparo dos alimentos, identificadas, acondicionadas em sacos plásticos e hermeticamente fechadas. As sobras do dia anterior de cada animal eram pesadas, identificadas, armazenadas separadamente em outro recipiente de plástico, que em seguida era lacrado. Procedimento similar era realizado com as fezes, porém em quantidade diferente, correspondente a $20 \%$ do total diário excretado.

As análises dos teores de matéria seca (MS), cinzas, proteína bruta (PB) e extrato etéreo ( $\mathrm{EE}$ ) nas amostras de alimento, sobras e fezes foram realizadas segundo AOAC (1990). O teor de matéria orgânica (MO) foi estimado deduzindo-se o teor de cinzas do valor de matéria seca. As frações fibra em detergente neutro (FDN) e fibra em detergenteácido (FDA) foram determinadas pela metodologia proposta por Van Soest et al. (1991). Os carboidratos totais (CT) e os carboidratos não-fibrosos (CNF) foram calculados segundo Sniffen et al. (1992) e os nutrientes digestíveis totais (NDT), a partir da FDA, conforme descrito por Rofler \& Satter (1975), citados pelo NRC (1989), enquanto a hemicelulose correspondeu à diferença entre FDN e FDA.

Os taninos foram determinados pelo método de FolinDenis, como descrito por Magalhães et al. (1997). O perfil de minerais foi avaliado por espectrofotometria de absorção atômica e o cálculo dos consumos e dos coeficientes de digestibilidade (CD) foram realizados segundo Schneider \& Flatt (1975), utilizando-se a fórmula abaixo:

$$
\mathrm{CD}=\frac{[\text { (oferecido- rejeitado) }- \text { excretado }]}{\text { (oferecido }- \text { rejeitado })} \times 100
$$

O delineamento experimental foi inteiramente casualizado, com cinco tratamentos e quatro repetições. Os dados foram analisados utilizando-se os procedimentos GLM (General Linear Models) e REG (Regression) (SAS, 1996). A escolha dos modelos de regressão foi realizada pelo seu grau de ajuste, com base no coeficiente de determinação ajustado (adj-R2), na significância da regressão, testada pelo teste $\mathrm{F}$, e na significância dos coeficientes de regressão pelo teste t. 


\section{Resultados e Discussão}

Os consumos de MS, MO, PB, FDN, FDA, hemicelulose e carboidratos totais apresentaram resposta quadrática $(\mathrm{P}<0,05)$ aos níveis de farelo de melancia forrageira nas dietas (Tabela 2). Os consumos de MS foram estatisticamente semelhantes entre si nos níveis intermediários de farelo de melancia forrageira (35 a 65\%) e mais elevados que aqueles observados nos níveis extremos (20 e 80\%). A ingestão de matéria seca das dietas mais consumidas atendeu à exigência de 500,0 g de MS/dia preconizada pelo NRC (1985). Nos pontos de máximo consumo de MS, equivalentes aos níveis de 66; 65,2 e 50\%, essa tendência se manteve e a exigência preconizada pelo NRC (1985) foi atendida em $100 \%$ e superada em $8,4 \%$. Os maiores consumos de matéria orgânica foram obtidos com o nível médio de $66 \%$ de inclusão de farelo de melancia forrageira, enquanto a ingestão máxima de proteína bruta foi observada no nível médio de $69 \%$ de farelo de melancia forrageira. O teor médio de proteína bruta das dietas (18,61\%), levemente acima do recomendado pelo NRC (1985), proporcionou consumo próximo ao de $81,0 \mathrm{~g}$ de $\mathrm{PB} / \mathrm{dia}$, que representou 95\% da exigência de 85,0 g de PB/dia (NRC, 1985), entretanto, no ponto de máximo consumo, essa exigência foi superada em $13 \%$.

O consumo de extrato etéreo não foi afetado pelos níveis de farelo de melancia forrageira. O consumo médio de EE das dietas testadas $\left(44,38 \mathrm{~g} /\right.$ dia e $\left.6,15 \mathrm{~g} / \mathrm{kg}^{0,75}\right)$, no entanto, foi superior ao verificado por Gonzaga Neto et al. (2001), de 21,7 g/dia e 1,97 g/ $\mathrm{kg}^{0,75}$, para dietas à base de feno de catingueira. De fato, os teores de extrato etéreo das dietas neste trabalho foram bastante superiores aos das dietas contendo feno de catingueira, o que indica que, quando alimentados com rações com farelo de melancia forrageira, os ovinos mostraram tolerância a níveis mais elevados de extrato etéreo.

Os consumos médios de FDN, FDA e hemicelulose neste trabalho foram inferiores aos verificados por Gonzaga Neto et al. (2001) em pesquisa com feno de catingeira. Esses autores encontraram em ovinos consumos médios de 354,8; 269,5 e 89,0 g/dia e de 32,23; 24,3 e 8,0 g/ $/ \mathrm{kg}^{0,75}$, o que pode estar associado à variação na qualidade da fibra entre as dietas testadas, uma vez que o feno de guandu, por ter sido confeccionado com a planta inteira picada, possuía na sua composição física partículas de caule e ramos, material de degradação mais difícil.

À exceção do consumo de carboidratos não-fibrosos, que foi linear e positivo, indicando interação digestiva para este parâmetro, provavelmente como resultado do efeito dos níveis de farelo de melancia forrageira, não foi verificado efeito associativo, uma vez que os dados comprovaram comportamento quadrático para o consumo. Os níveis de carboidratos não-fibrosos aumentaram entre as dietas, com variação de $8,98 \%$ entre o maior e o menor nível de farelo de melancia forrageira. O maior consumo de carboidratos não-fibrosos obtido com o nível de 65\% de inclusão (94,8 g/dia, 10,50 g/kg0,75 e 0,74\%PV) não ocasionou distúrbio digestivo nas condições deste experimento. Ressalta-se que os consumos de matéria seca neste estudo foram levemente superiores ao requerimento descrito pelo NRC (1985), pois houve redução no consumo de MS nos níveis máximos de inclusão (20 e 80\% de farelo de melancia forrageira).

A linearidade de consumo dos carboidratos nãofibrosos (CNF) com a variação dos níveis de farelo de melancia forrageira indicou também a ocorrência de interações digestivas quando os consumos foram expressos em $\mathrm{g} / \mathrm{kg}^{0,75}$ e \%PV. De fato, entre os carboidratos nãofibrosos, incluem-se os componentes da fração mais digestível dos carboidratos, como açúcares, amido, pectina e outros menos importantes de reserva, que são rapidamente convertidos em glicose pelos microrganismos ruminais, que os utilizam para crescimento gerando ácidos graxos voláteis, principalmente ácidos propiônico, acético e butírico, e alterando o $\mathrm{pH}$ ruminal e a digestibilidade da fibra. A demanda metabólica controla o consumo (Forbes, 2000), portanto, a redução no consumo no mais alto nível de farelo de melancia forrageira $(80 \%)$ poderia ter sido conseqüência desse efeito.

Gonzaga Neto et al. (2001) verificaram comportamento linear decrescente dos consumos de MS, MO e FDN com o aumento do nível de feno de catingueira em dietas para ovinos. Quando a incorporação da forrageira atingiu o nível de $100 \%$, os resultados de consumo foram semelhantes. Contudo, o consumo geral ficou aquém do recomendado e os autores atribuíram essa limitação aos elevados níveis de tanino das dietas estudadas (3,15 a 6,30\%).

Neste trabalho, no entanto, os teores de tanino foram menos elevados e variaram de 2,51 a 4,16\% entre o maior e o menor nível de farelo de melancia forrageira na dieta. O menor consumo da ração com $80 \%$ de farelo de melancia forrageira não pode ser atribuído ao teor de tanino, mas ao baixo teor de fibra e à elevada digestibilidade média da MS (58\%), que pode ter favorecido o atendimento das necessidades energéticas dos animais em menores níveis de consumo. Por outro lado, o baixo consumo da dieta com $20 \%$ de farelo de melancia forrageira pode ter sido ocasionado pela combinação dos efeitos do elevado teor de tanino (4,16\%) e de lignina do feno de guandu (FDN 59,18\%), os quais limitam a ingestão voluntária em ruminantes pela 


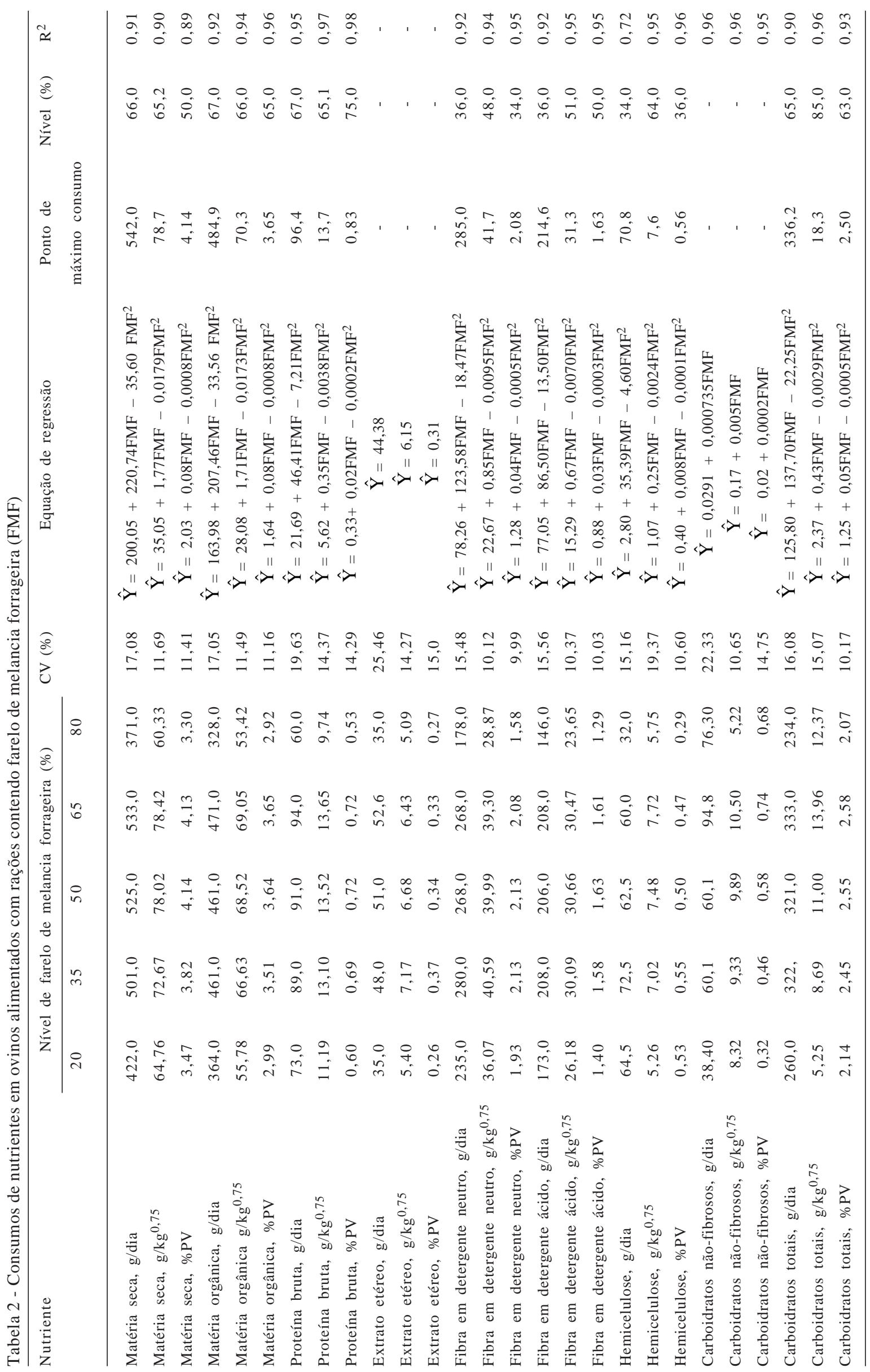


inibição da aceitabilidade, decorrente do tanino, ou pelo enchimento físico do rúmen, relacionado aos teores de fibra.

Gonzaga Neto et al. (2001) verificaram ainda consumos máximos de carboidratos totais, que teoricamente representariam a maior fração da fibra dietética, incluindo a FDN, de 336,2 g/dia, $18,3 \mathrm{~g} / \mathrm{kg}^{0,75}$ e $2,50 \% \mathrm{PV}$, que corresponde em média a $62 \%$ da matéria seca da dieta. Neste trabalho, a ingestão de MS das dietas mais consumidas satisfez as exigências nutricionais em níveis de 100\% e superou em 0,20 e 6,6\% respectivamente. Segundo Van Soest (1991), o consumo voluntário de matéria seca é altamente correlacionado ao teor de carboidratos (FDN) da dieta, por isso, o teor de FDN deveria se situar entre 55 e $60 \%$ da matéria seca do alimento. O valor encontrado neste trabalho (62\%) foi bastante semelhante ao preconizado por esses autores, provavelmente em razão do satisfatório comportamento ingestivo.

O consumo médio diário de água e o consumo médio total de água não foram influenciados $(\mathrm{P}>0,05)$ pelos níveis de farelo de melancia forrageira (Tabela 3 ). As dietas foram formuladas com ingredientes de elevado conteúdo de matéria seca (farelo e feno), porém não ocorreram restrições ou elevação no consumo diário de água dos ovinos (1,82 kg), considerado normal (NRC, 1985) para a faixa etária e de peso dos animais utilizados neste experimento.

Os níveis de farelo de melancia forrageira não influenciaram a digestibilidade de MS, PB, EE e FDN (Tabela 4).
Com o aumento do nível desse alimento na dieta, os coeficientes de digestibilidade da MO, FDA e carboidratos totais apresentaram comportamento linear crescente, de 54 a $62 \%$; 36 a $49 \%$ e 47 a 58\%, respectivamente. Portanto, o aumento dos níveis de farelo de melancia forrageira melhoraram a digestibilidade aparente destas frações, em decorrência da diminuição proporcional dos componentes da parede celular nas dietas, material de degradação mais lenta. A inclusão de farelo de melancia forrageira influenciou também o coeficiente de digestibilidade da hemicelulose, que teve comportamento linear decrescente (de 62 para $15 \%)$, evidenciando que, quanto maior o nível de farelo de melancia forrageira na dieta, menor a digestibilidade aparente da hemicelulose. Esse comportamento do coeficiente de digestibildiade da hemicelulose pode ter decorrido de alterações na população microbiana do rúmen proporcionadas pelos altos teores de carboidratos rapidamente degradados do farelo de melancia forrageira e teve como conseqüência menor atividade fibrolítica, ocasionada por alterações de pH e pelo menor tempo de permanência da digesta no rúmen. Assim, nos animais ruminantes, a digestão da parede celular pela microbiota ruminal é um processo relativamente lento e a máxima digestão da fração fibrosa depende do período de exposição da forragem à ação microbiana. Qualquer fator que leve à diminuição no tempo de exposição ou a redução da atividade dos microrganismos resultará em perda de parede celular potencialmente

Tabela 3 - Consumo médio diário de água (CMDA) e consumo médio total de água (CMTA) nos níveis de farelo de melancia forrageira

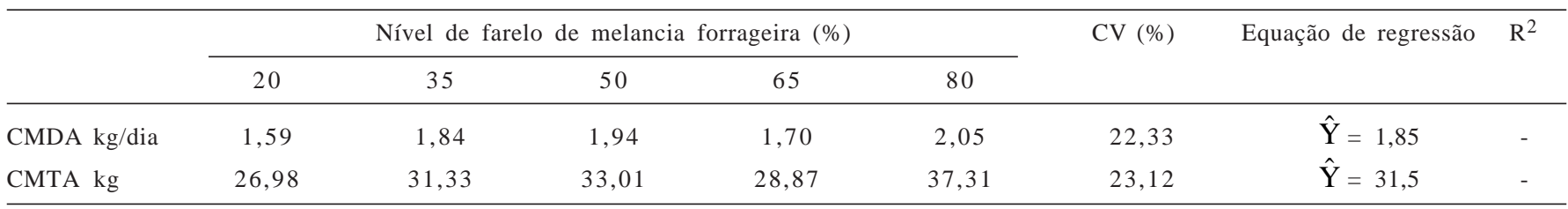

Tabela 4 - Coeficientes de digestibilidade (\%) dos nutrientes nos níveis de farelo de melancia forrageira nas dietas

\begin{tabular}{|c|c|c|c|c|c|c|c|c|}
\hline & \multicolumn{5}{|c|}{ Nível de farelo de melancia forrageira (\%) } & CV (\%) & Equação de regressão & $\mathrm{R}^{2}$ \\
\hline Matéria seca & 56 & 55 & 58 & 60 & 59 & 6,39 & $\hat{\mathrm{Y}}=58,0$ & - \\
\hline Matéria orgânica & 54 & 55 & 55 & 59 & 62 & 6,22 & $\hat{\mathrm{Y}}=63,09+1,95 \mathrm{FMF}$ & 0,86 \\
\hline Proteína bruta & 70 & 66 & 68 & 73 & 67 & 3,55 & $\hat{\mathrm{Y}}=69,0$ & - \\
\hline Extrato etéreo & 81 & 83 & 86 & 86 & 87 & 4,00 & $\hat{Y}=85,0$ & - \\
\hline Fibra em detergente ácido & 36 & 38 & 39 & 46 & 49 & 6,63 & $\hat{\mathrm{Y}}=51,98+3,4 \mathrm{FMF}$ & 0,91 \\
\hline Hemicelulose & 62 & 45 & 33 & 35 & 15 & 4,53 & $\hat{\mathrm{Y}}=6,73-10,38 \mathrm{FMF}$ & 0,64 \\
\hline Carboidratos totais & 47 & 50 & 49 & 51 & 58 & 8,42 & $\hat{\mathrm{Y}}=57,77+2,20 \mathrm{FMF}$ & 0,77 \\
\hline
\end{tabular}


digerível nas fezes e redução na sua digestibilidade (Minson, 1990).

Por outro lado, a concentração mais elevada de hemicelulose (18,18\%) na dieta com menor nível de farelo de melancia forrageira resultou em maior coeficiente de digestibilidade dessa fração, provavelmente pelo efeito oposto, ou seja, o maior teor de fibra poderia ter possibilitado melhores condições de subsistência e maior atuação da microbiota fibrolítica e sua atividade refletido em mais elevado coeficiente de digestibilidade da hemicelulose (62,0\%).

Os coeficientes de digestibilidade da matéria seca (MS) situaram entre 58,76 e 62,84\%, valores similares aos obtidos por Woodward \& Reed et al. (1995), com Acacia brevispica, Sesbania sesban e Vicia dasycarpa. Os coeficientes de digestibilidade da matéria orgânica (MO) medidos neste trabalho foram inferiores aos encontrados por Krishnamoorthy et al. (1995) para Gliricidia maculata (66,60\%), mas próximos aos obtidos com Leucaena leuсосерhala (62,0\%).

Os coeficientes de digestibilidade da MS, PB, EE e FDN não comprovaram efeitos associativos, similarmente aos consumos. Por outro lado, os coeficientes de digestibilidade de MO, FDA e carboidratos totais foram linearmente crescentes e influenciados pelo nível de farelo de melancia forrageira, segundo as seguintes equações, respectivamente: $\hat{\mathrm{Y}}=63,09+1,95 \mathrm{FMF}, \mathrm{R}^{2}=0,86 ; \hat{\mathrm{Y}}=51,98+3,4 \mathrm{FMF}, \mathrm{R}^{2}=0,91$; $\hat{\mathrm{Y}}=57,77+2,20 \mathrm{FMF}, \mathrm{R}^{2}=0,77$. O coeficiente de digestibilidade da hemicelulose foi severamente reduzido nos maiores níveis de farelo de melancia forrageira, logo a proporção de farelo de melancia forrageira na dieta afetou a digestibilidade da fração fibrosa, conforme representado pela equação: $\hat{Y}=6,73-10,38 \mathrm{FMF} ; \mathrm{R}^{2}=0,64$.

\section{Conclusões}

As dietas experimentais à base de farelo de melancia forrageira e feno de guandu apresentam digestibilidades satisfatórias e proporcionam consumos de matéria seca adequados para atender às exigências nutricionais de ovinos em crescimento. O farelo de melancia forrageira pode ser indicado para compor dietas à base de feno de guandu em níveis de 35 a 66\% da matéria seca.

\section{Agradecimentos}

À professora $\mathrm{Dr}^{\mathrm{a}}$. Maria Spínola Miranda da Faculdade de Farmácia (UFBA), que colaborou com este trabalho realizando as análises de taninos totais.

\section{Literatura Citada}

OFFICIAL METHODS OF ANALYSIS - AOAC. Association of Official Analytical Chemists. 15.ed. Washington, D.C.: 1990. 150p.

CÂNDIDO, M.J.D. Produção animal no semi-árido brasileiro. In: REUNIÃO ANUAL DA SOCIEDADE BRASILEIRA DE ZOOTECNIA, 42., 2005, Goiânia. Anais... Goiânia: Sociedade Brasileira de Zootecnia, 2005. (CD-ROM).

FORBES, J.M. Physiological and metabolic aspects of feed intake control. In: D'MELO, J.P.F. (Ed.) Farm animal metabolism and nutrition. Wallingford: $C A B$ International, 2000. p.319-334.

GOMIDE, C.A.M.; RANGEL, J.H.A.; MUNIZ, E.N. et al. Alternativas alimentares para ruminantes. Aracaju: Embrapa Tabuleiros Costeiros, 2006. 206p.

GONZAGA NETO, S.; BATISTA, A.M.V.; CARVALHO, F.F.R. et al. Composição bromatológica, consumo e digestibilidade in vivo de dietas com diferentes níveis de feno de catingueira (Caesalpinea bracteosa), fornecidas para ovinos Morada Nova. Revista Brasileira de Zootecnia, v.30, n.2, p.553-562, 2001.

KRISHNAMOORTHY U.; SOLLER, H.; STEINGAS, S. et al. Energy and protein evaluation of tropical feedstuffs for whole tract and ruminal digestion by chemical analyses and rumen inoculum studies in vitro. Animal Feed Science and Technology, v.52, p.177-188, 1995.

MAGALHÃES, P.C.; RODRIGUES, W.A.; DURÃES, F.O.M. Tanino no grão de sorgo: bases fisiológicas e métodos de determinação. Sete Lagoas: EMBRAPA-CNPMS, 1997. 26p. (Circular Técnica, 27).

MINSON, D.J. Forage in ruminant nutrition. San Diego: Academic Press, 1990. 482p.

NATIONAL RESEARCH COUNCIL - NRC. Nutrient requirements of sheep. 6.rev.ed. Washington, D.C.: National Academy of Sciences, 1985. 99p.

NATIONAL RESEARCH COUNCIL - NRC. Nutrient requeriments of dairy cattle. Washington, D.C.: National Academy of Sciences, 1989. 158p.

STATISTICAL ANALYSIS SYTEMS - SAS. User's guide: Stat, Version 6.11 Cary: 1996.

SCHNEIDER, B.H.; FLATT, W.P. The evaluation of feeds through digestibility experiments. Georgia: The University of Georgia Press, 1975. 423p.

SILVA, D.S.; CASTRO, J.M.C.; MEDEIROS, A.N. et al. Feno de Maniçoba em dietas para ovinos: consumo de nutrientes, digestibilidade e balanço nitrogenado. Revista Brasileira de Zootecnia, v.36, n.5, p.1685-1690, 2007 (supl.).

SILVA, R.L.N.V. Composição química, consumo e digestibilidade aparente de dietas contendo diferentes níveis de farelo de melancia forrageira (Citrullus lanatus cv. Citroides e feno de guandu (Cajanus Cajan cv. D1 Type), em ovinos. 2003. 74f. Dissertação (Mestrado em Medicina Veterinária Tropical) - Universidade Federal da Bahia, Salvador.

SNIFFEN, C.J.; O'CONNOR, J.D.; Van SOEST P.J. et al. A net carbohydrate and protein system for evaluating cattle diets: II. Carbohydrate and protein availability. Journal of Animal Science, v.70, p.3562-3577, 1992.

Van SOEST, P.J.; ROBERTSON, J.B.; LEWIS, B.A. Methods of dietary fiber, neutral detergent fiber and non-starches polysaccharides in relation to animal nutrition. Journal of Dairy Science, v.74, p.3582-3597, 1991.

VERAS, R.M.L.; FERREIRA, M.A.; VERAS, A.S.C. et al. Substituição do milho por farelo de palma forrageira em dietas para ovinos em crescimento: consumo e digestibilidade. Revista Brasileira Zootecnia, v.34, n.1, p.351-356, 2005.

WOODWARD, A.; REED, J.D. Intake and digestibility for sheep and goats consuming supplementary Acacia brevispica e Sesbania sesban. Animal Feed Science and Technology, v.56, p.207-216, 1995. 